\title{
Intestinal immune cells in Strongyloides stercoralis infection
}

\author{
Anete Trajman, Thomas T MacDonald, Celeste C S Elia
}

\begin{abstract}
Background-Strongyloides stercoralis can cause a wide spectrum of disease in man, ranging from a chronic asymptomatic infection to a hyperinfective, often fatal syndrome. In rodents, spontaneous expulsion of Strongyloides spp occurs after experimental infection. Mast cells, goblet cells, and eosinophils have been identified as possible effectors of this expulsion.
\end{abstract}

Aims-To investigate intestinal histopathology and mucosal immunity in immunocompetent patients with chronic $S$ stercoralis infection.

Methods-Jejunal biopsies were performed in 19 immunocompetent patients with a positive stool examination for $S$ stercoralis and few or no symptoms, and in seven healthy controls. Specimens were processed for histopathological analysis and stained by the immunoperoxidase technique, using the following monoclonal antibodies: CD2, CD3, CD4, CD8, anti-T cell receptor (TcR) $\gamma / \delta$, RFD1 and RFD7 (two different macrophage markers), $\mathrm{Ki67+}$ (proliferating) cells, antihuman leucocyte antigen (HLA)-DR, and anticollagen IV. In addition, CD25+ cells, mast cells, IgE expressing cells, calprotectin containing cells, and neutrophil elastase positive cells were stained by the alkaline phosphatase method.

Results-Jejunal morphology and the numbers of different $T$ cell subsets, mast cells, IgE expressing cells, eosinophils, and goblet cells were unaffected by $\boldsymbol{S}$ stercoralis infection. Conversely, the numbers of mature macrophages and dividing enterocytes in the crypts were reduced significantly. Crypt enterocytes did not express HLA-DR in both groups. The expression of HLA-DR by villus enterocytes was also comparable in patients and controls. There were no activated $(\mathrm{CD} 25+)$ cells in the mucosa of either patients or controls.

Conclusions-Compared with seven healthy uninfected volunteers, a group of 19 Brazilians with clinically mild strongyloides infection showed no abnormality of mucosal structure and no increase in nonspecific inflammatory cells. Likewise, there was no increase in mucosal $T$ cells or macrophages.

(F Clin Pathol 1997;50:991-995)

Keywords: Strongyloides stercoralis; mucosal immunity; T lymphocytes
Strongyloides stercoralis is a common intestinal parasite throughout the world, and is endemic in developing countries. ${ }^{1}$ Following cutaneous infection by $S$ stercoralis larvae, chronic asymptomatic infection can occur, with survival of adult worms in the human intestine for several years. ${ }^{2}$ Within the intestine, rhabditiform noninfective larvae may develop into invasive filariform larvae and cause autoinfection, which is peculiar to the life cycle of strongyloides. ${ }^{3}$ Under immunosuppressive conditions, the state of equilibrium can be broken and a hyperinfective, often fatal syndrome may occur. ${ }^{4}$

Little is known about the immunomodulatory mechanisms that regulate the interaction between this parasite and its host in man. In contrast, rodent infection by Nippostrongylus brasiliensis, Strongyloides ratti, and Trichinella spiralis elicits an intestinal immune response that eliminates the adult worm from the intestine. Mast cells, goblet cells, and eosinophils have been identified as possible effectors of this expulsion..$^{5-7}$ In man, high titres of specific antistrongyloides $\operatorname{IgG}, \operatorname{IgM}$, and $\operatorname{IgA}$ and peripheral eosinophilia have been associated with protection against severe infection. ${ }^{8}$ Nevertheless, the level of specific antibodies does not correlate with the severity of infection. Surprisingly, the number of intestinal IgA bearing plasma cells has been reported to be reduced in severe infection, but a cause and effect relation has not been proven. ${ }^{9}$ Other components of the mucosal immune response have not been evaluated in strongyloidiasis.

We used immunhistochemistry to analyse mucosal immunity in 19 immunocompetent patients with chronic $S$ stercoralis infection with few or no symptoms and in seven healthy controls. Jejunal morphology and the numbers of different $T$ cell subsets, mast cells, eosinophils and goblet cells were unaffected by $S$ stercoralis infection. Conversely, the number of mature macrophages and of dividing enterocytes in the crypts was reduced. The absence of an immune response may prevent architectural damage of the mucosa and the development of immune mediated diarrhoea.

\section{Methods}

PATIENTS

Nineteen patients with at least one positive stool Baerman examination for $S$ stercoralis infection were accrued from the outpatient clinics of the University Hospital of the Federal University of Rio de Janeiro, Brazil. Patients with other simultaneous intestinal parasites and those with the acquired immune deficiency 
Table 1 Monoclonal antibodies used for immunohistochemistry

\begin{tabular}{lllll}
\hline Recognised cell & Antibody & Origin & Code & Dilution \\
\hline CD2+ & RFT11 & RFH & - & $1 / 3$ \\
CD3+ & UCHT1 & UCH & - & Non-diluted \\
CD4+ & CD4 & Dako & MT310 & $1 / 50$ \\
CD8+ & RFT8 & RFH & - & $1 / 3$ \\
IL-2 receptor & CD25 & Dako & M731 & $1 / 40$ \\
TCR $\gamma / \delta$ & TCR $\delta$-1 & T Cell Sciences & 160 B05.0 & $1 / 100$ \\
Dividing cells & Ki67 & Dako & M722 & $1 / 50$ \\
Collagen IV & Collagen IV & Dako & M785 & $1 / 100$ \\
IgE & Polyclonal & Dako & A094 & $1 / 100$ \\
Mast cell & Mast cell tryptase & Dako & M7052 & $1 / 50$ \\
Neutrophils & Neutrophil elastase & Dako & M752 & $1 / 100$ \\
Myeloid/Hystiocyte & Calprotectin & Dako & M747 & $1 / 50$ \\
HLA-DR & HLA-DR & Dako & M704 & $1 / 40$ \\
CD45+ & PD7 & Dako & MO855 & $1 / 50$ \\
Second layer & Rabbit antimouse & Dako & PO260 & $1 / 50$ \\
Third layer & Goat antirabbit & Dako & PO448 & $1 / 50$ \\
\hline
\end{tabular}

RFH, Royal Free Hospital, London, UK; UCH, University College Hospital, London, UK; Dako, High Wycombe, Bucks, UK; T Cell Sciences, Cambridge, Massachusetts, USA.

syndrome or other immunological disorders were excluded from the study. Their mean age was 47.5 years (range 29-67 years), 10 were black, and 11 were male. Eleven patients were asymptomatic, and the diagnosis was suspected either by the presence of blood eosinophilia or during routine stool tests. The remaining eight patients had mild symptoms, such as epigastric pain (four patients), urticaria (one patient), and self limited short term diarrhoea (three patients). Four patients had taken $\mathrm{H}_{2}$ receptor antagonists during the previous year, a group of drugs known to predispose to $S$ stercoralis infection. ${ }^{10}$

The control group comprised seven healthy volunteers. Strongyloides stercoralis infection was ruled out by four negative stool examinations (including the Baerman method in all four specimens), a normal white cell blood count, a negative serology for strongyloides antibodies (enzyme linked immunosorbent assay), and a negative search for the parasite in the jejunal juice. Their mean age was 22 years (range 19-24 years). Four were male, and six were white.

The study was approved by the Ethical Committee of the University Hospital. All patients and controls gave informed consent to participate in the study.

\section{IMMUNOHISTOCHEMISTRY}

Jejunal biopsies were obtained with a Watson capsule near the angle of Treitz under fluoroscopic control. Specimens were divided into two portions. The first one was fixed in $10 \%$ formal saline and embedded in paraffin wax. Sections were cut at $6 \mu \mathrm{m}$ intervals and stained by haematoxylin and eosin for histopathological analysis. Villus height and crypt depth were measured and reported in micrometres. Eosinophils were counted in the lamina propria of at least five $\times 400$ magnification fields and goblet cells were counted per 500 epithelial nuclei in villi and crypts separately. The second portion was mounted in OCT compound, snap frozen, sectioned at $6 \mu \mathrm{m}$ intervals, and promptly fixed in chloroform/acetone (1/1) for 20 minutes. Sections were stained for CD2, CD3, CD4, CD8, T cell receptor (TcR) $\gamma / \delta$, macrophage markers (RFD1, antigen presenting cells; RFD7, mature macrophages), Ki67+ (proliferating cells), major histocompatibility complex (MHC) class II molecule (human leucocyte antigen (HLA)-DR), and collagen IV by the three stage immunoperoxidase procedure. ${ }^{11}$ In addition, CD25+ cells, mast cells, IgE expressing cells, calprotectin containing cells (Mac 387+), and neutrophil elastase positive cells were stained by the alkaline phosphatase method. ${ }^{11}$ Sequential double staining with both techniques was used as described previously to identify CD8-/TcR $\gamma / \delta+$ lymphocytes and CD3-/CD45+ non-T cells. ${ }^{12}$ Table 1 lists the monoclonal antibodies used and their sources. Positive cells were estimated separately in the lamina propria and epithelium. Intraepithelial lymphocytes were counted and are expressed over a total of 500 nuclei. CD2, CD3, CD4, CD8, RFD1, and RFD7 positive cells in the lamina propria were counted in a Dialux 20EB light optic microscope using a Seescan Image Analyser (Seescan, Cambridge, UK) in 10 different areas. A mean count was obtained and data were expressed in cells $\times 10^{4} / \mu \mathrm{m}^{2}$. Other cells, fewer in the lamina propria, were counted and were expressed per low power field $(\times 250)$ or high power field $(\times 400)$, as indicated. Proliferating cells were counted in at least three well oriented crypts and data are displayed as mean positive cells/crypt. The thickness of the basement membrane was measured after staining of collagen IV and this is expressed in micrometres. HLA-DR expression was estimated by a semiquantitative method according to a scale graded from + (very faint staining) to ++++ (intense expression).

Means of the two groups were compared using the Student's $t$ test for normally distributed data; the Wilcoxon test was used if the sample did not follow a normal distribution. The majority of the groups contained normally distributed data but for those in which the data were not consistent with a normal distribution, a Bonferroni correction suggested that this could be due to chance. Accordingly, and for clarity of presentation, data are shown as geometric means and $95 \%$ confidence intervals.

\section{Results}

The jejunal morphology was normal for the standards of developing countries. ${ }^{13}{ }^{14}$ Crypts were long in the mucosa of some subjects in both groups, but the mean crypt depths of patients and controls was similar (table 2). The mean numbers of total $T$ cells and their subsets were similar in both groups in the epithelium and lamina propria (tables 3 and 4, respectively). Nonetheless, when compared with normal Western standards $(<80 / 500$ epithelial cells), the numbers of total CD2+ and CD3+ intraepithelial $\mathrm{T}$ lymphocytes were increased in both patients and controls (fig 1). The numbers of mature macrophages (RFD7+, table 5) and dividing $(\mathrm{Ki} 67+)$ cells was reduced in the infected group: patients, 24.24 cells/crypt; controls, 38.05 cells/crypt $(p=0.01)$. The density of the other cell types was similar in both groups. Neutrophil elastase: patients, 10.48 cells/low power field; controls, 17.36 cells/low power field $(p=0.61)$. Mast cells: patients, 0.77 cells/high power field; 
Table 2 Histopathological results

\begin{tabular}{lllllll}
\hline & Villus height $(\mu \mathrm{m})$ & Crypt depth $(\mu \mathrm{m})$ & Basement membrane $(\mu \mathrm{m})$ & $\begin{array}{l}\text { Eosinophils } \\
\text { (cells/hpf) }\end{array}$ & Goblet cells villus $^{*}$ & \multicolumn{1}{c}{ Goblet cells crypt* } \\
\hline Controls & $331(229$ to 426$)$ & $144(122$ to 174$)$ & $19.1(14.5$ to 24$)$ & $2.5(1.3$ to 4.6$)$ & $21.4(17.8$ to 26.9$)$ & $79.4(67.6$ to 93.3$)$ \\
Patients & $346(295$ to 393$)$ & $132(112$ to 153$)$ & $17(15$ to 18.8$)$ & $3.8(2.3$ to 5.4$)$ & $22.9(19.7$ to 27.2) & $64.6(53.1$ to 74.1$)$ \\
\hline
\end{tabular}

Values are geometric means ( $95 \%$ confidence intervals).

*cells/500 epithelial cells.

hpf, high power field.

Table 3 Numbers of intraepithelial lymphocytes

\begin{tabular}{|c|c|c|c|c|c|c|c|}
\hline & $C D 2$ & $C D 3$ & $C D 4$ & $C D 8$ & $\gamma^{\prime} / \delta^{*}$ & $C D 8-; \delta+$ & $C D 3-C D 45+$ \\
\hline Controls & $125(100$ to 138$)$ & $109.6(87$ to 134$)$ & 20.4 (12.9 to 37.1$)$ & $100(81.3$ to 138$)$ & $14.8(4.3$ to 30.2$)$ & $0.12(0$ to 0.25$)$ & $0.9(0.3$ to 1.4$)$ \\
\hline Patients & $109.6(93.3$ to 131.8$)$ & $104.7(64.6$ to 134.8$)$ & 26.3 (20.4 to 33.1 ) & $93.3(72.4$ to 120.2$)$ & 10.5 (8.1 to 13.5$)$ & $0.07(0.03$ to 0.09$)$ & $0.6(0.3$ to 0.9$)$ \\
\hline Ratio & 0.87 & 0.95 & 1.29 & 0.71 & 0.58 & 0.58 & 0.7 \\
\hline
\end{tabular}

Values are geometric means ( $95 \%$ confidence intervals) of positive cells $/ 500$ nuclei or per high power field ${ }^{\star}$.

Table 4 Numbers of lamina propria lymphocytes

\begin{tabular}{lllll}
\hline & $C D 2$ & $C D 3$ & $C D 4$ & $C D 8$ \\
\hline Controls & $14.8(9.8$ to 21.9$)$ & $19.1(10$ to 32.4$)$ & $9.6(7.4$ to 12.6$)$ & $3.1(2$ to 4.3$)$ \\
Patients & $17.4(15.1$ to 18.6$)$ & $19.9(15.7$ to 24.2$)$ & $8.9(7.4$ to 10.1$)$ & $3.1(2.5$ to 4.0$)$ \\
Ratio & 1.2 & 1.04 & 0.92 & 1.0
\end{tabular}

Values are geometric means ( $95 \%$ confidence intervals) of positive cells $/ 10^{4} \mu \mathrm{m}^{2}$.

Table 5 Numbers of lamina propria macrophages and neutrophils

\begin{tabular}{lllll}
\hline & $R F D 1$ & $R F D 7^{*}$ & $L 1$ & Elastase \\
\hline Controls & $3.9(2.1$ to 7.2$)$ & $8.9(6$ to 13.8$)$ & $6.2(0$ to 24.2$)$ & $4.8(1.4$ to 30.5$)$ \\
Patients & $3.3(2.2$ to 5.1$)$ & $5.5(4.7$ to 6.2$)$ & $3.4(2.2$ to 5.1$)$ & $6.9(4.3$ to 12.9$)$ \\
Ratio & 0.8 & 0.6 & 0.55 & 1.4
\end{tabular}

Values are geometric means ( $95 \%$ confidence intervals) of positive cells $/ 10^{4} \mu \mathrm{m}^{2}$ or per field $(\times 250)^{\star}$.

controls, 0.35 cells/high power field $(\mathrm{p}=0.70)$. IgE+ cells: patients, 1.38 cells/high power field; controls, 0.40 cells/high power field $(p=0.91)$. The thickness of the basal membrane (patients, 17.03); controls, $19.24 \mu \mathrm{m}(\mathrm{p}=0.22,95 \%$ confidence interval -1.41 to 5.83 ) and the expression of HLA-DR by enterocytes (patients, 3.39; controls, $3.29(\mathrm{p}=0.99)$ ) was also comparable in patients and controls. Crypt enterocytes did not express HLA-DR. There were no activated (CD25+) cells in the mucosa of either patients or controls. The results are summarised in tables $2-5$.

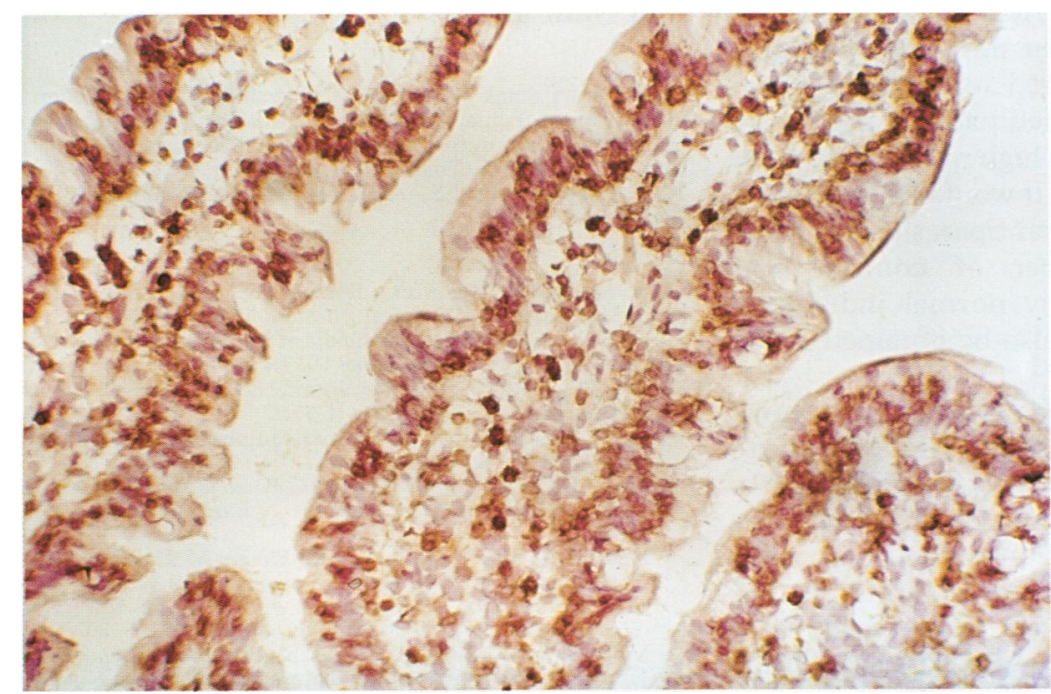

Figure 1 CD2 immunostaining of the intestinal mucosa of a patient. $T$ cells in the lamina propria and epithelium are positive. There is a massive infiltration of intraepithelial lymphocytes. (Original magnification $\times 200$.)

\section{Discussion}

The understanding of the immunomodulatory mechanisms by which $S$ stercoralis is maintained in check in normal individuals, but causes an overwhelming opportunistic infection in immunosupressed individuals, is of key importance. There are virtually no studies in humans on the roles of different intestinal effector cells in the defence mechanisms of the normal host against $S$ stercoralis. The understanding of this state of "tolerance" is an important step to elucidate the pathogenesis of the hyperinfection syndrome. Here, we provide a detailed histopathological and immunological study of the intestinal mucosa of patients with mild infection by $S$ stercoralis. In these patients, the jejunal architecture was not affected by the parasite. Villus height, crypt depth, and the villus:crypt ratio were comparable in both groups. The normal intestinal morphology is based on a dynamic process in which crypt enterocytes mature and migrate to the top of the villi. The basal membrane has a crucial role in this process. Accordingly, the thickness of the basal membrane in the infected group was comparable to the control group.

Usually, villous atrophy is associated with crypt hyperplasia as a compensatory mechanism. The number of dividing cells in our patients was, on the contrary, reduced. Crypt hypoplasia can cause villous atrophy, as seen in malnutrition. ${ }^{13}$ However, because there was no mucosal damage in our patients, this result must be interpreted with caution. The absence of a hyper-regenerative state is probably more meaningful. Other signs of inflammation, such as increased HLA-DR expression by enterocytes or its expression by crypt enterocytes were also lacking. There were increased numbers of CD3+ intraepithelial lymphocytes in both patients and local controls when compared to the normal standards in the Western world. ${ }^{15}$ This has been reported in developing countries before and has been ascribed to the constant challenge of the contaminated environment. ${ }^{14} 16$ Because controls have the same pattern, this cannot be attributed to the presence of the parasite. The distribution of different $T$ cell phenotypes was unchanged, with CD4+ cells in the lamina propria and CD8+ cells in the epithelium. Animal models have shown that CD4+ cells play an important role in the defence against nematodes. ${ }^{17}$ In our 
infected patients, however, no increase in these çells was seen. Nevertheless, some degree of antigen processing and subsequent recognition by $T$ cells must occur, because patients with strongyloidiasis have serum specific antibodies of the IgA and IgE isotypes, ${ }^{18}$ which are T cell dependent. However, it is possible that this humoral response occurs during the larval preintestinal migration.

Recently, there has been a great interest in the heterogeneous population of intraepithelial lymphocytes. In normal jejunum, most of them are CD $8+$ and $10 \%$ express the TcR $\gamma / \delta .{ }^{19}$ The function, if any, of $\mathrm{TcR} \gamma / \delta+$ intraepithelial lymphocytes remains unknown. Spencer et al recently described two different phenotypes of intraepithelial lymphocytes. ${ }^{12}{ }^{15}$ The numbers of non-T cells (CD3-/CD7+) were found to be decreased in coeliac disease. In our patients, there was no such change. All subsets of $T$ and non- $T$ cells were similar in patients and controls. There is increasing evidence that activated $T$ cells play an important role in the pathogenesis of enteropathy. ${ }^{20}$ The absence of CD25+ cells in the specimens suggests that there is no cell activation in the mucosa in $S$ stercoralis infection, thus explaining the normal structure of the mucosa.

Features of an immediate IgE mediated hypersensitivity response were also investigated. In rodents, it has been suggested that after $\operatorname{IgE}$ recognition of the parasite antigens, mast cells degranulate and mucous secretion by goblet cells is stimulated. Worms would then be entrapped in the mucous and expelled. $^{6}$ In Jamaican children with the trichuris dysentery syndrome, there are greater numbers both of mast cells and cells with surface IgE than are found in local controls. ${ }^{21}$ In addition, there is degranulation of mast cells and increased histamine release in parasitised children. Although this reaction is not sufficient to cause expulsion of the large worm burden, it is probably involved in the pathogenesis of the syndrome. Despite the passage of frequent bloody stools and the presence of large worm burdens in the caecum, there are no other signs of significant mucosal inflammation in these children. ${ }^{16}$ As a group, there was no significant increase in mast cells or IgE+ cells in patients compared to controls. However, within the 17 infected patients there were a few who had extremely high numbers of these cell types in the mucosa. It would be premature to ascribe this to an antiparasite response because, if the number of controls was increased, perhaps a few normal individuals with high values would also be obtained in the larger sample size.

Regarding non-specific immunity, the numbers of mature macrophages (RFD7+) were decreased in the patients with strongyloides. In addition, there was a trend, although not statistically significant, towards reduced numbers of cells recognised by calprotectin, an antibacterial glycoprotein found in tissue infiltrating monocytes, neutrophils, and eosinophils. ${ }^{22} \mathrm{An}-$ tigen presenting cells (RFD1+) were not altered in the infected group. Neutrophils, recognised by neutrophil elastase, were also simi- lar in both groups. On the contrary, MacDonald and co-workers have found an increased number of macrophage containing tumour necrosis factor (TNF) $\alpha$ in children with trichuris dysentery syndrome. ${ }^{23}$

Taken together, our data suggest that human mild $S$ stercoralis infection does not elicit a significant intestinal inflammatory response. This scarcity of pathology explains the paucity of gastrointestinal symptoms and the maintenance of a long term infection. A similar tolerance of the parasite by the host is seen during murine Heligmosomoides polygyrus infection. Adult worms survive in the intestine of mice for several months following primary infection by larvae. $H$ polygyrus infection also inhibits the usual immune response to concomitant unrelated parasites, thus favouring the survival of other species. In a series of elegant experiments using low burdens of $H$ polygyrus larvae, Behnke and colleagues demonstrated that this parasite can be expelled if an appropriate intestinal inflammatory response is mounted against $T$ spiralis during concomitant infection, suggesting that $H$ polygyrus is not primarily resistant to the immune response. ${ }^{24}$ The authors conclude that $H$ polygyrus has an immunomodulatory effect on the host, although there is some degree of resistance to the immune attack.

It is likely that in humans, $S$ stercoralis has a similar survival strategy, downregulating the host's protective immunity, as suggested by the results presented here. As a matter of fact, Genta et al reported a decreased lymphocyte blastogenic response to larval $S$ stercoralis antigens in infected patients. ${ }^{25}$ The response was stronger if cells were cultured in normal rather than autologous serum, suggesting that there are inhibitory factors for cell mediated immunity in the serum of infected patients. Genta has also speculated that it is the molting effect of steroids on rhabditiform larvae-and not immunosuppression-that predisposes to dissemination. ${ }^{26}{ }^{27}$ Further studies are necessary to determine if and how massive $S$ stercoralis infection breaks tolerance and to elucidate the etiopathogenesis of the dissemination syndrome.

The authors thank Dr Edgar M Carvalho, from the Federal University of Bahia, who performed the anti-strongyloides serologies in the control group. This work was supported in part by grants from Coordenação de Aperfeiçoamento de Pessoal de Nivel Superior (CAPES-AEX1789/94-5) and Fundação José Nivel Sup

1 de Messias IT, Telles FQ, Boaretti AC, Sliva S, Guimarres LM, Genta RM. Clinical, immunological and epidemiological aspects of strongyloidiasis in an endemic area of Brazil. Allergol Immunopathol 1987;15:37-41.

2 Gill GV, Bell DR. S. stercoralis infection in former Far East prisoners of war. $B M \mathcal{F} 1979 ; 1: 572$.

3 Faust EC, DeGroat A. Internal autoinfection in human strongyloidiasis. Am $\mathcal{F}$ Trop Med 1940;20:359-70.

4 Cruz T, Rebouças G, Rocha H. Fatal strongyloidiasis in patients receiving corticosteroids. $N$ Engl f Med 1966;275: 1093-6.

5 Nawa Y, Kiyota M, Korenaga M, Kotani M. Defective protective capacity of $\mathrm{W} / \mathrm{W}^{\mathrm{v}}$ mice against Strongyloides ratti infection and its reconstitution with bone marrow cells. infection and its reconstitution
Parasite Immunol 1985;7:429-38.

6 Miller HRP, Huntley JF, Wallace GR. Immune exclusion and mucus trapping during the rapid expulsion of Nippostrongylus brasiliensis from primed rats. Immunology 1981; 44:419-29.

7 Wang CH, Korenaga M, Greenwood A, Bell RG. Thelper subset function in the gut of rats: differential stimulation of 
eosinophils, mucosal mast cells and antibody-forming cells by OX- and OX22- and OX8- OX22+ cells. Immunolog 1990;71:166-75.

8 Badaró R, Carvalho EM, Santos RB, Gam AA, Genta RM Parasite-specific humoral responses in different clinical forms of strongyloidiasis. Trans $R$ Soc Trop Med Hyg 1987; 81:149-50.

9 Fogaça H, Elia CCS, Madi K, Oliveira A. Estudo das imunoglobulinas intestinais na estrongiloidiase. Folha Médica (BR) 1990;101:229-35.

10 Gianella RA, Broitman SA, Zamcheck N. Influence of gastric acidity on bacterial and parasitic enteric infections. Ann Intern Med 1973;78:271-6.

11 Isaacson PG, Wright DH. Immunocytochemistry of lymphoreticular tumors. In: Polak JM, van Noorden S, eds. Immunocytochemestry. Practical applications in pathology and biology. Bristol: John Wright \& Sons, 1986:568-98.

12 Spencer J, MacDonald TT, Diss TC, Walker-Smith JA, Ciclitira PJ, Isaacson PG. Changes in intraepithelial lymphocytes subpopulations in coeliac disease and enteropathy associated to $\mathrm{T}$ cell lymphoma (malignant histiocytosis of the intestine). Gut 1989;30:339-46.

13 Sprintz H, Sribhibhadh R, Gangarosa EJ, Benyajati C, Kundel D, Halstead S. Biopsy of small bowel of Thai people. With special reference to recovery from Asiatic cholera and to an intestinal malabsorption syndrome. Am f Clin Pathol to an intestinal mal

14 Ramalingaswami V. Perspectives in protein malnutrition. Nature 1964;201:546-51.

15 Spencer J, Isaacson PG, Walker-Smith JA, MacDonald TT. Heterogeneity in intaepithelial lymphocyte subpopulations in fetal and postnatal human small intestine. $\mathcal{F}$ Pediatr Gastroenterol Nutr 1989;9:173-7.

16 MacDonald TT, Choy MY, Spencer J, Richman PI, Diss T, Hanchard B, et al. Histopathology and immunohistochemestry of the caecum in children with the Trichuris dysentery syndrome. F Clin Pathol 1991;44:194-9.

17 Urban JF Jr, Katona IM, Finkelman FD. Heligmosomoides polygyrus: $\mathrm{CD} 4+$ but not $\mathrm{CD} 8+\mathrm{T}$ cells regulate the $\mathrm{IgE}$ response and protective immunity in mice. Exp Parasitol 1991;73:500-11.

18 Genta RM, Gatti S, Linke JM, Cevini C, Scaglia M. Endemic strongyloidiasis in Nothern Italy: clinical and epidemiological aspects. $Q \mathcal{F}$ Med $1988 ; 257: 679-90$

19 Spencer J, Issacson PG, Diss TC, MacDonald TT. Expression of disulphide linked and non-disulphide linked forms of the $T$ cell receptor gamma/delta heterodimer in human intraepithelial lymphocytes. Eur f Immunol 1989;19:13359.

20 MacDonald TT, Spencer J. Evidence that activated mucosal $T$ cells play a role in the pathogenesis of enteropathy in $T$ cells play a role in the pathogenesis of enteropathy
human small intestine. $\mathcal{F}$ Exp Med 1988;167:1341-9.

21 Cooper ES, Spencer J, Whyte-Alleng CAM, Cromwell O, Whitney $\mathrm{P}$, Venugopal $\mathrm{S}$, et al. Immediate hypersensitivity in colon of children with chronic Trichuris trichiura dysentery. Lancet 1991;338:1104-7.

22 Brandtzaeg P, Jones DB, Flavell DJ, Fagerhol MK. Mac 387 antibody and detection of formalin resistant myelomonocytic Ll antigen. F Clin Pathol 1988;41:963-70.

23 MacDonald TT, Spencer J, Murch SH, Choy M-Y, Venugopal S, Bundy DAP, et al. Immunoepidemiology of intestinal helminthic infections. 3. Mucosal macrophages and cytokine production in the colon of children with Trichuris trichiura dysentery. Trans $R$ Soc Trop Med Hyg 1994; 88:265-8.

24 Behnke JM, Cabaj W, Wakelin D. Susceptibility of adult Heligmosomoides polygyrus to intestinal inflammatory responses induced by heterologous infection. Int $\mathcal{f}$ Parasitol 1992;22:75-86.

25 Genta RM, Ottesen EA, Neva FA, Walzer PD, Tanowitz $\mathrm{HB}$, Wittner M. Cellular responses in human strongyloidiasis. Am ₹ Trop Med Hyg 1983;32:990-4.

26 Genta RM. Dysregulation of strongyloidiasis: a new hypothesis. Clin Microbiol Rev 1992;5:345-55.

27 Genta RM. Immunobiology of strongyloidiasis. Trop Geogr Med 1984;36:223-9. 